\title{
Association between pulse wave velocity from velocity-encoded MRI and advanced diastolic function indices assessed by speckle tracking strain analysis in Diabetes Mellitus type 1
}

\author{
Linda D van Schinkel', Dominique Auger, Saskia G van Elderen, Nina Ajmone Marsan, Victoria Delgado, \\ Arnold CT Ng, Jan W Smit, Jeroen J Bax, Albert de Roos, Jos J Westenberg
}

From 2011 SCMR/Euro CMR Joint Scientific Sessions

Nice, France. 3-6 February 2011

\section{Introduction}

Increased pulse wave velocity (PWV), a marker for aortic stiffness, has been linked to worse outcome such as heart failure. This potent marker can be accurately assessed with velocity-encoded MRI according to the transit-time method (Grotenhuis. JMRI 2009). Whether an increase in PWV translates in early diastolic dysfunction in diabetic patients remains unexplored.

\section{Purpose}

Evaluate the association between PWV and diastolic function indices in patients with diabetes type1 (DM1).

\section{Methods}

First normal values for age-related PWV were determined. Twenty-five healthy volunteers (age range 18-65years) were recruited and PWV-values of the total aorta were assessed with velocity-encoded MRI using a 1.5T MRI scanner (Philips, Best, the Netherlands). Linear regression between PWV and age defined normal values.

Next, PWV was assessed in 17 consecutive DM1 patients (mean age $48 \pm 8$ years). PWV was defined increased when the age-related value exceeds the normal value by $2 \times$ standard error (SE). Patients underwent subsequent $2 \mathrm{D}$ echocardiography for assessment of conventional diastolic function indices (isovolumetric relaxation time (IVRT), transmitral early (E) and atrial (A) peak filling velocities, E/A-ratio, E-deceleration time (DT)).

LUMC, Leiden, Netherlands

Full list of author information is available at the end of the article
Color-coded tissue Doppler imaging was applied to the 4-chamber view to determine mean mitral annulus velocity (E'). Furthermore, longitudinal speckle tracking strain analysis using apical 4-/2-/3-chambers views was performed to derive advanced diastolic indices [peak transmitral E-wave to strain rate during isovolumic relaxation (SRIVR)] and left atrium (LA) systolic strain. Subsequently, ratios of peak transmitral E-wave to mean $E^{\prime}\left(E / E^{\prime}\right)$ and of peak transmitral E-wave to strain rate during isovolumic relaxation (E/SRIVR) were calculated.

\section{Results}

Normal PWV age-relation was determined by linear regression in volunteer data: $\mathrm{PWV}=\mathrm{A} \times \mathrm{AGE}+\mathrm{B}$, with $\mathrm{A}$ $\pm S E=0.03 \pm 0.01 \mathrm{~m} / \mathrm{s} /$ year and $\mathrm{B} \pm \mathrm{SE}=3.70 \pm 0.46 \mathrm{~m} / \mathrm{s}$. In 17 DM1 patients, significant correlation was found between PWV and SRIVR and LA strain (Figure 1). A total of 7 patients showed increased age-related PWV. Mean PWV and echocardiographic diastolic function indices for patients with increased PWV $(\mathrm{n}=7)$ and for patients with normal PWV $(\mathrm{n}=10)$ are presented in Table 1. Interestingly, conventional echocardiographic indices were similar between both patient groups whereas advanced diastolic function indices SRIVR, E/SRIVR and LA strain were significantly different (Table 1).

\section{Conclusions}

In patients with DM1, increased PWV is correlated with advanced diastolic function indices determined by speckle tracking strain analysis. Increased MRI PWV may translate in early left ventricular diastolic dysfunction. 

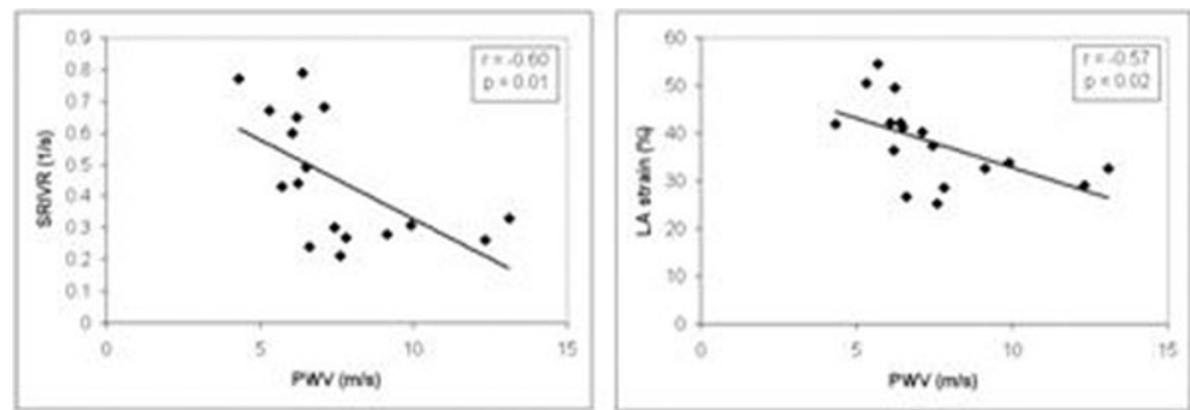

Figure 1 Association between PWV and SRIVR and LA strain.

Table $1 \mathrm{MRI}$ and echocardiographic results

\begin{tabular}{llll}
\hline & $\begin{array}{l}\text { Normal PWV } \\
(\mathbf{N}=10)\end{array}$ & $\begin{array}{l}\text { Increased PWV } \\
(\mathbf{N}=\mathbf{7})\end{array}$ & p-value \\
\hline PWV (m/s) & $6.0 \pm 0.8$ & $9.6 \pm 2.3$ & $0.006^{*}$ \\
IVRT (ms) & $76 \pm 10$ & $84 \pm 30$ & 0.52 \\
E/A (-) & $1.3 \pm 0.3$ & $1.0 \pm 0.2$ & 0.08 \\
DT (ms) & $214 \pm 50$ & $235 \pm 51$ & 0.43 \\
SRIVR (1/s) & $0.58 \pm 0.17$ & $0.28 \pm 0.04$ & $<0.001^{*}$ \\
E/E' (-) & $9 \pm 2$ & $11 \pm 2$ & 0.11 \\
E/SRIVR (cm) & $146 \pm 47$ & $285 \pm 78$ & $<0.001^{*}$ \\
LA strain (\%) & $43 \pm 8$ & $31 \pm 4$ & $0.003^{*}$ \\
\hline
\end{tabular}

\section{Acknowledgement}

Funded by Netherlands Heart Foundation (Project UL 2009-4548).

Published: 2 February 2011

doi:10.1186/1532-429X-13-S1-P63

Cite this article as: van Schinkel et al: Association between pulse wave velocity from velocity-encoded MRI and advanced diastolic function indices assessed by speckle tracking strain analysis in Diabetes Mellitus type 1. Journal of Cardiovascular Magnetic Resonance 2011 13(Suppl 1):P63.

Submit your next manuscript to BioMed Central and take full advantage of:

- Convenient online submission

- Thorough peer review

- No space constraints or color figure charges

- Immediate publication on acceptance

- Inclusion in PubMed, CAS, Scopus and Google Scholar

- Research which is freely available for redistribution

Submit your manuscript at www.biomedcentral.com/submit
C Biomed Central 